\title{
A Precision Navigation System for Public Transit Users
}

\author{
Masaki Ito, Satoru Fukuta, Takao Kawamura, and Kazanuri Sugahara \\ Graduate School of Engineering, Tottori University, \\ 4-101 Koyamacho-Minami Tottori-shi, Tottori 680-8522, Japan \\ \{masaki, s072041, kawamura, sugahara\}@ike.tottori-u.ac.jp
}

\begin{abstract}
In this paper, we propose a context aware navigation for public transportation users. In the travel with public transportation, a user needs to switch several modality of moving such as walking, waiting at the station, and riding a vehicle. We developed a navigation system that automatically detect user's state how he/she is using public transportation, and then provide suitable information for each state. We developed the system as an Android application, and demonstrate its basic functionality in the field experiment with five examinees.
\end{abstract}

\section{Introduction}

Public transport is important infrastructure for modern society. The benefit of public transportation is not only for personal convenience, but also for society such as reduction of traffic jam, reduction of carbon dioxide. Therefore it is important to promote the use of public transportation for citizens including a person who normally uses a car. However, a person who seldom use public transportation or a stranger in the area faces great difficulties when he/she is trying to take a train or a bus. There are already many web services that provide information about public transportation such as timetables or an itinerary from the certain station to the destination. We have also developed and operating such kind of web service called "Busnet", where a user can plan a path on a public transportation network in Tottori Prefecture, Japan [1]. However, such web services are designed for a user who is planning to move a certain place, but does not guide a person who has exactly started to move to the destination.

We developed a navigation system for a smartphone that guide a passenger of public transportation in real-time. The system provides suitable information for a passenger in each situations of his/her travel just like a turn-by-turn navigation system that guides a driver. Comparing with the travel with a car which existing turn-by-turn navigation system support, travel with public transportation is much more complex, therefore we need to investigate the process of the travel with public transportation before designing the navigation system.

\section{Information Technology for Public Transportation}

With the recent development in information technologies, various IT services which do not necessarily have strong relation to the existing intelligent trans- 
portation systems (ITS) for the users of public transportation is arising [2] 3] [4] [5]. Unlike existing ITS whose primary target is infrastructure such as managing road and operating trains and buses, arising services aim more gpassengercentrich style in its feature. For example, Google provides gGoogle Transith which plans the trip between arbitrary two places including trains, buses and walking as a feature of Google Maps. A traveler searches for the best itinerary on the service, and move to the destination with the information.

Some researches point out that users feel less secure while the trip with railways or buses [6] [7], however, most existing IT services to support users of public transportation mainly focus on the planning process before the usage of buses or railways, and does not support on-board users to railways or route buses. In contrast there are rich support for car driver through automotive navigation system while traveling in this decade. One reason is that there are no reasonable device to support passenger of trains and buses, but a smartphone is changing the situation. The other reason is the process to travel with trains or buses is much complicated than the travel with a car. There are several research projects to support on-board traveler [8] 9, but these products are still not in the practical use.

We studied the process to travel with public transportation, then we classified the process into the following three steps: walking, waiting and riding. Figure 1 illustrates the state diagram of the process. Firstly, a user walks to the bus stop or the station. Then he/she buys a ticket and wait for the vehicle. He/she takes the vehicle when the vehicle arrives at the station or the bus stop. In the vehicle, he/she stays until the vehicle arrives at the destination. After getting off the vehicle, he/she walks to the destination, or changes to another bus or train.

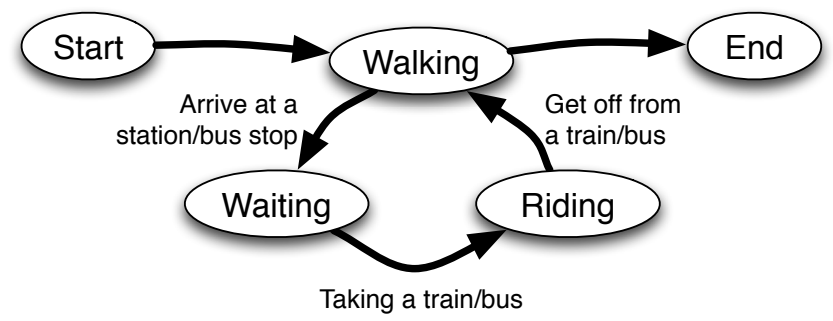

Fig. 1. State diagram in traveling with public transportation

\section{A Precision Navigation System}

Based on the study in the former section, we developed a context aware navigation system for public transport users that automatically switches three different modalities for navigation. We developed the navigation system as an application for an Android smartphone. The navigation system recognizes user's situation 
automatically with timetables and GPS, then provides suitable information for each step. As dividing a user's sequence of using public transport into three states and providing different information for each state, we accomplished a useful navigation system for public transport users.

\subsection{Navigation for Walking}

When a user is walking, a user needs information of his/her location, or map information around his/her location. Therefore the system provides a map and shows a route to the bus stop or the station where the user ride a vehicle. It also gives a turn-by-turn navigation to the station of the bus stop. Figure 2 illustrates the screenshot. In the upper part of the screen, it gives the information of the bus or the train he/she will ride. In the lower part of the screen, it provides a map with a route information and scenery around the bus stop or the station as a photograph in order to easily correlate direction with the surroundings of the user.

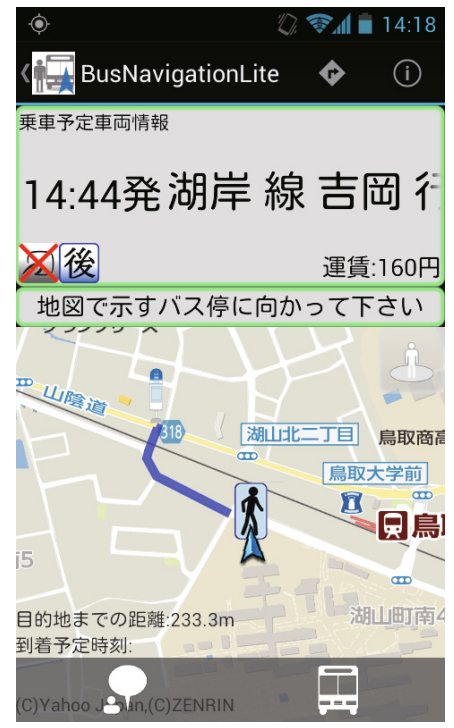

route to the bus stop

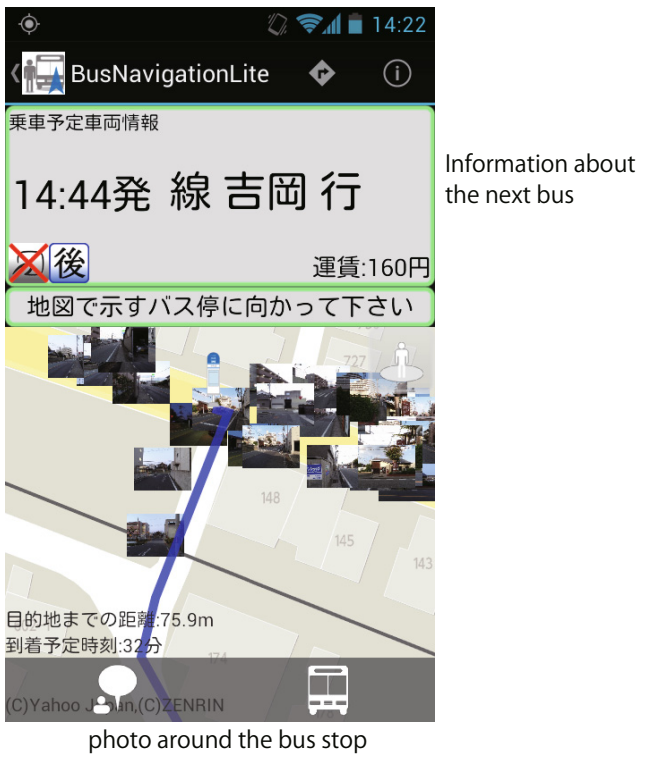

photo around the bus stop

Fig. 2. Navigation for walking to the bus stop

\subsection{Navigation for Waiting for the Bus or the Train}

While waiting for the bus or the train, a passenger needs to understand the system of the public transportation, and prepare for riding such as buying a ticket. Then he/she needs to go to the exact place to take the train or the bus such as a certain platform of the station. He/she may want to do something 
if there is enough time before the departure. The proposed navigation system gives guidance how to spend at the station or the bus stop with certain priority. Figure 3 illustrates the screenshot. The system countdown the departure time of the train in the lower part of the screen, or gives a detailed map around the station or the bus stops.

The system of public transportation is different even within the same country. For example, some route buses ask a user to pay when riding, but other route buses ask to pay when getting off. With the proposed system, a user is never confused by the difference of the system.

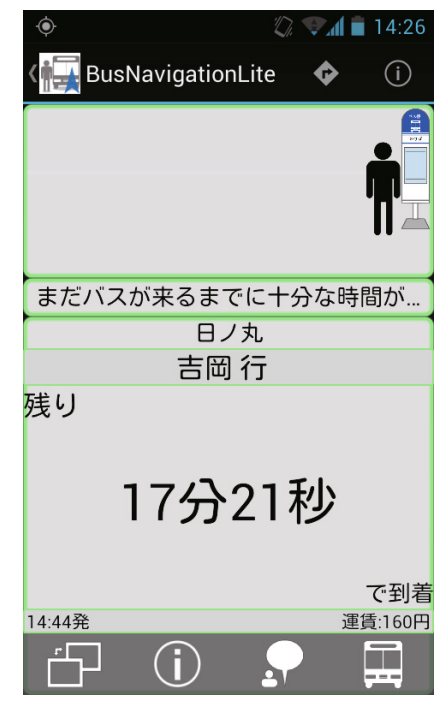

Countdown to the departure

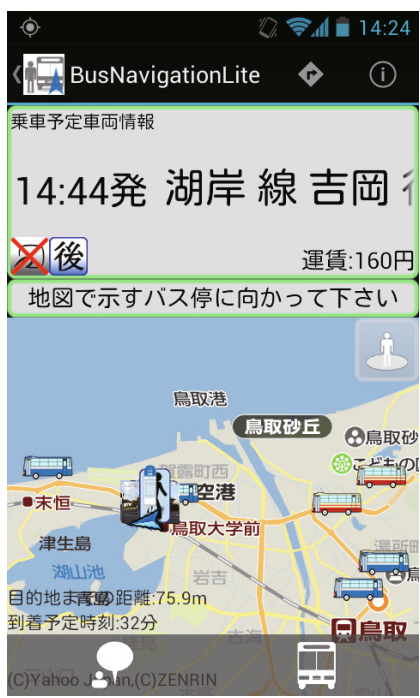

Location of comming route buses

Fig. 3. Navigation while waiting for a bus or a train

\subsection{Navigation for Riding a Bus/Train}

After the user ride a vehicle, the navigation system shows a map and route to the destination. Figure 4 illustrates the screen. When a passenger is arriving at the destination, the system alerts the user to get off. If he/she must transfer to another bus or train, the system guides the transit after taking off the vehicle. A passenger tends to feel anxiety if he/she is taking the right train or bus. The navigation system reduces the anxiety, and enables prediction of arrival time.

\section{Field Experiment}

We conducted field experiment of the prototype system. Five examinees made a round-trip to the AEON shopping mall from the Tottori University campus with 


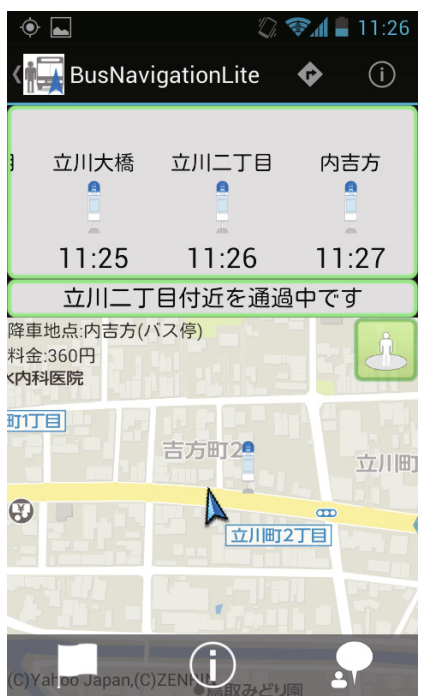

Guidance of the bus route

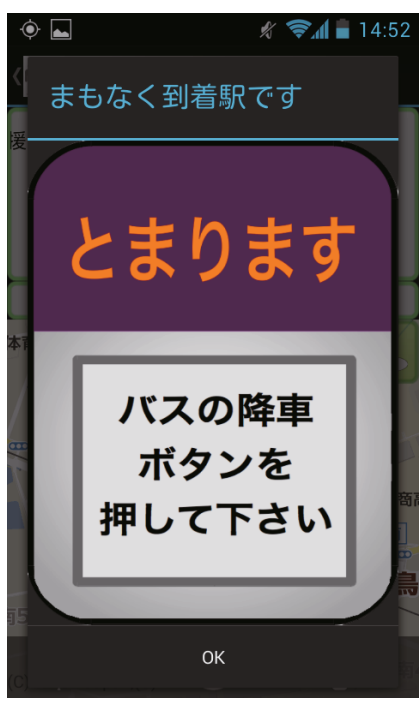

Inform to push the bell

Fig. 4. Navigation for riding a bus or a train

the prototype system, and answered to the questionnaire after the travel. The trip is approximately $5 \mathrm{~km}$ including walking, riding a route bus and changing to another route bus at the bus stop. Table 1 is the detailed condition of the experiment.

Table 1. Field Experiment

\begin{tabular}{l|l}
\hline \hline Examinees & 5 male (including students and a staff of bus company) \\
Devices & Google Galaxy Nexus for each examinee \\
To the AEON mall & 54 min in total, 1 transfer, 6 min walk \\
From the AEON mall & 36 min in total, 0 transfer, 14 min walk \\
\hline
\end{tabular}

\subsection{Basic Functionality}

The prototype system worked fine as we designed while the experiment. Since the frequency of the report of the vehicle location is one minute, detection of user's condition in the trip sometimes delays.

\subsection{Result of the Questionnaire}

Table 2 is the result of the questionnaire to the examinees. They are the scores of five grade evaluations and variances in each navigation and overall quality of the 
Table 2. The Result of the Questionnaire

\begin{tabular}{|c|c|c|c|c|c|}
\hline & $\begin{array}{l}\text { Quality of } \\
\text { the prototype }\end{array}$ & $\begin{array}{l}\text { Easiness in inputting } \\
\text { the destination }\end{array}$ & $\begin{array}{l}\text { Navigation } \\
\text { for walking }\end{array}$ & $\begin{array}{l}\text { Navigation } \\
\text { while waiting }\end{array}$ & $\begin{array}{l}\text { Navigation } \\
\text { while riding }\end{array}$ \\
\hline & 3.60 & 4.00 & 4.60 & 4.00 & 4.00 \\
\hline Variance & 0.24 & 0.50 & 0.24 & 0.00 & 0.40 \\
\hline
\end{tabular}

prototype system. Though there was a problem in the quality of the prototypes, many examinee were satisfied with the navigation method in each condition.

From the free description in the questionnaire, we found that the examinees especially satisfied with the location information of the route bus that he/she was taking. Supporting an on-board user is one of the most important essence in the proposed system. therefore we can say that the comment verify our initial hypothesis.

\section{Summary}

In this paper, we developed a precision navigation system for using public transport. It is difficult to guide a user of public transport, since a user needs different information in each stage of moving with public transport. The system divides process of the travel with public transportation into three states, and provides different guidance for a user in each state.

As a future work, it is needed to improve the recognition of user's state. There is various possible information to recognize user's state such as user's location, vehicle's location, delay of transport, arrival time at the transport, distance from user's location to next point. We are using only user's location and arrival time of public transport now. We will improve the recognition, and provide the system as a practical service in Tottori Prefecture.

Acknowledgements. This research is supported by Strategic Information and Communications R\&D Promotion Programme (SCOPE), Ministry of Internal Affairs and Communications, Japan.

\section{References}

1. Kawamura, T., Sugahara, K.: Practical path planning system for bus network. IPSJ Journal 48(2), 780-790 (2007)

2. Giannopoulos, G.A.: The application of information and communication technologies in transport. European Journal of Operational Research 152(2), 302-320 (2004)

3. Camacho, T.D., Foth, M., Rakotonirainy, A.: Pervasive technology and public transport: Opportunities beyond telematics. Pervasive Computing 12, 18-25 (2013)

4. Arikawa, M., Konomi, S., Onishi, K.: NAVITIME: Supporting Pedestrian Navigation in the Real World. IEEE Pervasive Computing, 21-29 (2007)

5. Ferris, B., Watkins, K., Borning, A.: OneBusAway: Results from providing realtime arrival information for public transit. In: Proceedings of the 28th International Conference on Human Factors in Computing Systems, pp. 1807-1816. ACM (2010) 
6. Lyons, G., Harman, R.: The uk public transport industry and provision of multimodal traveller information. International Journal of Transport Management 1(1), $1-13(2002)$

7. Grotenhuis, J.W., Wiegmans, B.W., Rietveld, P.: The desired quality of integrated multimodal travel information in public transport: Customer needs for time and effort savings. Transport Policy 14(1), 27-38 (2007)

8. Zhang, L., Gupta, S.D., Li, J.Q., Zhou, K., Zhang, W.B.Z.: Path2go: Context-aware services for mobile real-time multimodal traveler information. In: 14th International IEEE Conference on Intelligent Transportation Systems (ITSC), pp. 174-179. IEEE (October 2011)

9. Carmien, S., Dawe, M., Fischer, G., Gorman, A., Kintsch, A., Sullivan, J., James, F.: Socio-technical environments supporting people with cognitive disabilities using public transportation. ACM Transactions on Computer-Human Interaction 12(2), 233-262 (2005) 